\title{
INCIDENCE OF PROTOTHECA SPP. IN MILK PRODUCED BY DAIRY HERDS IN ASSIUT CITY
}

\author{
M.N. EL-GENDI MARWA and M.T. ALI EL-SHREEF LAMIAA \\ Animal Health Research Institute, Assiut Regional Laboratory
}

\section{ABSTRACT}

Received at: $25 / 3 / 2013$

Accepted: 7/5/2013
Bovine mastitis associated with Prototheca is considered a rare pathology, but is increasing in prevalence all over the world and therefore becoming more relevant to the dairy industry. A total number of 150 random samples (100 of buffaloe's milk and 50 of cow's milk) were collected from dairy farms and dairy shops in Assiut city as well as from some villages around the city. Physical examination of all samples revealed absence of any visible abnormalities. California Mastitis Test (CMT) was carried out on all samples to detect the subclinical cases. $59 \%$ of buffaloes and $68 \%$ of cow's milk samples were positive. The average count of total yeasts and mold counts was $3.29 \times 10^{2}$ and $3.59 \times 10^{2}$ in examined samples of buffaloes and cow milk, respectively. Samples were examined for the presence of Prototheca spp. $12 \%$ of buffaloe`s milk samples were positive. On the basis of colony morphology and microscopic appearance, after incubation at $38^{\circ} \mathrm{C}$ for $48-72$ hrs, Prototheca spp. were isolated, identified and sub-cultured for further identification. $P$. zopfi and $P$. wickerhamii were foud in $7 \%$ and $5 \%$ of the positive samples-respectively. In addition, Prototheca spp. was not isolated from any of examined cow's milk samples. Antibiotics sensitivity test was carried out to detect antimicrobial susceptibility of isolated microorganisms.

Key Words: Prototheca spp., subclinical mastitis, dairyherds.

\section{INTRODUCTION}

Subclinical mastitis is the most serious type of diseases as the infected animal shows no obvious symptoms and secrets apparently normal milk for a long time, during which causative organisms spread infection in the herd, so it is an important feature of the epidemiology of many forms of bovine mastitis (Bakken and Gudding, 1982).

Mastitis caused by $P$. zopfii alge is a disease of high producing, machine-milked dairy cows. It occurs worldwide in tropical and temperate climatic areas, and mostly appears sporadically in a therapy-resistant forms. However, in poorly managed dairy herds it may be endemic, causing serious economic losses as a result of decreased milk quality and quantity and culling of infected animals (Ricchi et al., 2010).

The genus Prototheca consists of unicellular, aerobic, achlorophyllous, saprophytic algae with a wide distribution in natural environments. They have been isolated from such diverse sites as slime flux of trees, soil, animal faces and various aqueous sources including streams, rivers, lakes, marine water, fish ponds, swimming-pools and even tap water. They are ubiquitous inhabitants of domestic and municipal sewage and are seldom detected in sewage treatment systems. The algae can also be found in many food products, e.g. beef, pork, clams, crabs and dairy milk.
Eventually, Prototheca have been isolated from both wild and domesticated animals, they have been shown to transiently colonize human skin, fingernails, respiratory tract and digestive system. Though there are a variety of other sources from which they can be isolated, the main reservoir remains sewage water and animal waste (Pore et al., 1983; Huerre et al., 1993 and Wirth et al., 1999). Prototheca spp. is colorless unicellular algae that are opportunistic organisms, pathogenic for humans and animals (Acha and Szyfres, 2003).

The genus Prototheca was established and six species of Prototheca have been recognized: Prototheca moriformis; Prototheca stagnora; Prototheca ulemea; Prototheca wickerhamii; Prototheca zopfii; Prototheca blaschkeae. In 1952, P. zopfii was first identified as a pathogen of bovine mastitis associated with reduced milk production characterized by thin watery secretion with white flakes (Möller et al., 2007). Although sporadic cases of protothecal mastitis have been observed, endemic cases of this mastitis have been occurring in many countries around the world (Hodges et al., 1985; Costa et al., 1996; Aalbaek et al., 1998; Janosi et al., 2001). Microalgae of the genus Prototheca are closely related to the algal genus Chlorella but lack chlorophyll (Ueno et al., 2003; Roesler et al., 2006 and Ricchi et al., 2010). Though three species (P. zopfii, P. blaschkeae, and P. wickerhamii) can cause 
bovine mastitis, $P$. zopfii is the most common organism responsible for protothecal mastitis and the other two species could only cause sporadic cases (Marques et al., 2006 and Marques et al., 2008). Since $P$. zopfii was first identified as a pathogen of bovine mastitis in 1952, the incidence of mastitis due to this microalga is steadily increasing and gaining more and more economic and public health importance (Costa et al., 1996; Janosi et al., 2001 and Roesler and Hensel, 2003). P. zopfii strains are often associated with wet conditions and organic matters, and widely dispersed in dairy environments) (Costa et al., 1997; Buzzini et al., 2004 and Bueno et al., 2006).

Protothecosis has been reported in humans (gastroenteritis, bursitis, etc.) and in many other animal species. Bovine mastitis represents the main form of occurrence of protothecosis in cattle. Milk as well as dairy products, when contaminated with Prototheca spp., represent a potential means of transmission of this zoonosis disease. In humans these microorganisms have been associated with cutaneous lesions (Segal et al., 1976 and Venezio et al., 1982), gastroenteritis (Iacoviello et al., 1992 and Costa et al., 1995) and bursitis (Nosanchuk and Greenberg., 1973 and Abhel et al., 1980). Prototheca spp. have also been isolated from many other sources: blood, peritoneal abscesses (Cox et al., 1974), peritoneal fluid (Sands et al., 1991), liver (Chan et al., 1990), the blood of an immunocompromised child (Heney et al., 1991), from patients with AIDS (Kaminski et al., 1992 and Laeng et al., 1994) and from a patient with cancer (Gómez-Hernando et al., 1996).

The transmission of infection caused by the microalgae usually occurs by means of direct contact with contaminated sources. Studies on the in vitro susceptibility profile of the Prototheca genus have revealed great resistance to conventional antimicrobial and antifungal agents (Buzzini et al., 2004 and Tortorano et al., 2008). These microalgae do not respond to routine mastitis therapy, and the only control measure to date has been the elimination of the infected cows (Marques et al., 2006). However, some previous studies found in vitro susceptibility of $P$. zopfii strains to amphotericin B and nystatin, which are commonly used in human protothecosis therapy (Segal et al., 1976; Marques et al., 2006 and Tortorano et al., 2008). These findings led us to test the in vitro susceptibility of our $P$. zopfii strains to the two mentioned drugs. Meanwhile, some other conventional antimicrobial and antifungal agents were also chosen for the in vitro susceptibility test in the present study.

Considering the increasing importance that is being given to the Prototheca species, mainly due to the economic losses for which they are responsible (concerning basically dairy cattle breeding), as well as for representing a potential risk to public health, the purpose of this study was to examine the milk produced from dairy farms in Assiut for presence of Prototheca spp.

\section{MATERIALS and METHODS}

A) Collection, preparation and serial dilutions of samples: A total of 150 random samples of buffaloes and cow's milk were collected from different dairy farms and dairy shops in Assiut city to be examined in laboratory (100 samples of buffalo's milk and 50 samples of cow`s milk). All samples were tested by the CMT, and then kept at $4{ }^{\circ} \mathrm{C}$ to be examined microbiologically for presence of Prototheca spp. and total yeast and mold count. Eleven $\mathrm{ml}$ of each of the examined samples were mixed with $99 \mathrm{ml}$ of sterile $0.1 \%$ peptone water and thoroughly mixed to give a dilution of $1 / 10$, and then ten fold serial dilutions were carried out (A.P.H.A., 1992).

B) California Mastitis test (CMT) according to Schalm et al. (1971): Each $3 \mathrm{ml}$ of milk sample was drawn in shallow cups in the CMT paddle then approximately equal volume of $3 \mathrm{ml}$ of the commercial available CMT reagents was added to each cup and mixed together through swirling the paddle in a circular motion for few seconds. According to the visible reaction of the CMT, the results were classified into four scores: $0=$ negative or traces (no change in consistency), $1=$ slightly positive (+), $2=$ positive $(++)$ and $3=$ highly positive $(+++)$. Scores 1,2 and 3 depend on the degree of gellation that were indicated by gelatinous mass (Schuppel and Schwope, 1998).

C) Enumeration of total yeasts and molds according to Harrigan and MacCance (1976) by using malt extract agar (containing $500 \mathrm{mg}$ each of chlortetracycline and HCL chloramphenicol).

D) Isolation of Prototheca spp.: Aliquots of $100 \mu \mathrm{l}$ of milk were streaked on Sabouraud dextrose agar (SDA) plates. Streaked plates were incubated under aerobic conditions for $48 \mathrm{hrs}$. at $37{ }^{\circ} \mathrm{C}$. Yeast-like colonies (grayish and white to cream colored small colonies of $1 \mathrm{~mm}$ or 1-2 $\mathrm{mm}$ size, respectively, with yeast like appearance and odor were detected) were subcultured on SDA for $48 \mathrm{~h}$ at $37{ }^{\circ} \mathrm{C}$. Species identification of Prototheca was based mainly upon morphological characterization of pure cultures (fig.1), lactophenol cotton blue (LCB) stained smears and carbohydrate assimilation profiling. The microscopical observation of Prototheca cells stained with lactophenol cotton blue which showed a typical appearance with ovoid to globose sporangia with sporangiospores in several developmental stages (fig.2) suggesting that they could belong to a different Prototheca species. The morphological appearance observed for the Prototheca spp. was similar to 
previous description of other authors (Pore, 1998; DiPersio, 2001; Roesler et al., 2006).

E) Identification of Prototheca Spp.: Identification of Prototheca Spp. was carried out according to Dubravka et al. (2006) and Asfour and El-Metwally (2010). Streaked plates were incubated under aerobic conditions at $37^{\circ} \mathrm{C}$ for $48 \mathrm{~h}$ and monitored daily. From the growing colonies, wet microscopic smears, Gram and methylene blue stains were done. The preparations were examined using light and phasecontrast microscopy according to Cosmina et al.
(2009). Urease activity also applied to differentiate between Prototheca spp. and other yeasts.

F) Sensitivity test: Antimicrobial susceptibility of Prototheca spp. strains was tested by disk diffusion method on Müeller Hinton's agar as described in CLSI, 2004 (formerly NCCLS) document. The plates were incubated for 48 to $72 \mathrm{hrs}$ at $37^{\circ} \mathrm{C}$ and the inhibition diameters were measured. The following antifungal and antibacterial antibiotics were tested:, amphotericinB nystatin, kanamicin, penicillin, gentamicin, neomycin, streptomycin, ampicillin, and amoxicillin.

\section{RESULTS}

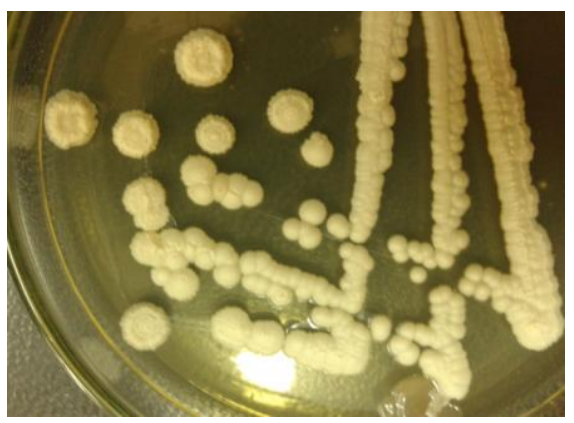

Fig. 1: Sabouraud dextrose agar plate showing the organism at $28^{\circ} \mathrm{C}$ for $96 \mathrm{hrs}$.

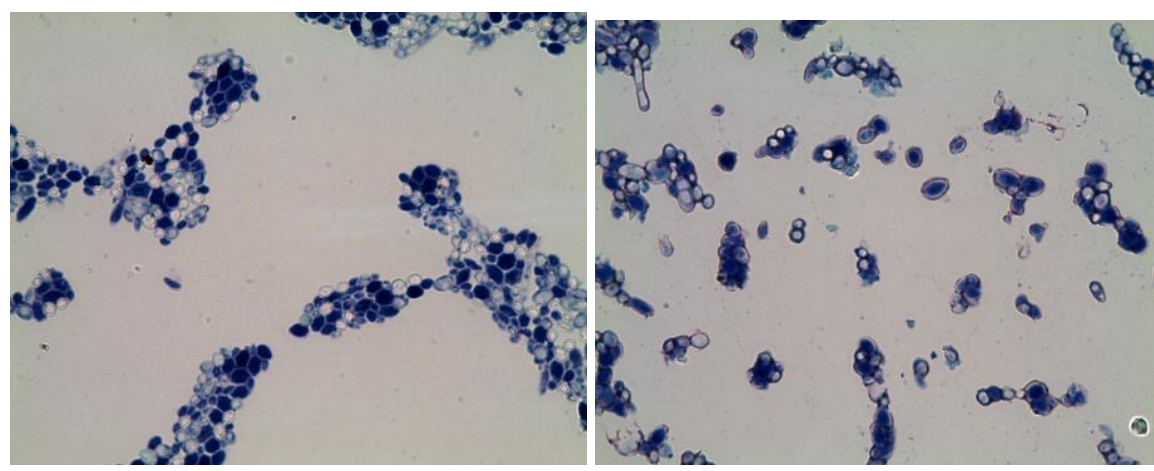

Fig 2: Micrographs of Prototheca spp. stained with methylene blue, 100 x magnification, grown on Sabouraud dextrose agar at $28^{\circ} \mathrm{C}$ for $96 \mathrm{hrs}$.

Table 1: Results of CMT on the examined samples.

\begin{tabular}{ccccc}
\hline \multirow{2}{*}{ Score } & \multicolumn{2}{c}{ Cow's milk } & \multicolumn{2}{c}{ Buffaloe's milk } \\
\cline { 2 - 5 } & No. of samples & $\%$ & No. of samples & $\%$ \\
\hline+++ ve & 6 & $12 \%$ & 15 & $15 \%$ \\
\hline++ ve & 7 & $14 \%$ & 21 & $21 \%$ \\
\hline+ ve & 21 & $42 \%$ & 23 & $41 \%$ \\
\hline -ve & 16 & $32 \%$ & 41 & $100 \%$ \\
\hline Total & 50 & $100 \%$ & 100 & $23 \%$ \\
\hline
\end{tabular}


Assiut Vet. Med. J. Vol. 59 No. 137 April 2013

Table 2: Statistical analytical results of total yeasts and molds count in the examined samples.

\begin{tabular}{ccccccc}
\hline \multirow{2}{*}{ Type of sample } & $\begin{array}{c}\text { No. of examined } \\
\text { samples }\end{array}$ & \multicolumn{2}{c}{ Positive samples } & \multicolumn{3}{c}{ Count /g } \\
\cline { 3 - 7 } & No. & $\%$ & Average & Max. & Min. \\
\hline Buffaloe's milk & 100 & 80 & $80 \%$ & $3.29 \times 10^{2}$ & $1.27 \times 10^{3}$ & $>10$ \\
\hline Cow's milk & 50 & 38 & $76 \%$ & $3.59 \times 10^{2}$ & $2.4 \times 10^{3}$ & $>10$ \\
\hline
\end{tabular}

Table 3: Frequency distribution of positive samples based on their total yeasts and molds count.

\begin{tabular}{ccccc}
\hline \multirow{2}{*}{ Count / g } & \multicolumn{2}{c}{ Buffaloes milk } & \multicolumn{3}{c}{ Cow milk } \\
\cline { 2 - 5 } & No. / 80 & $\%$ & No. / 38 & $\%$ \\
\hline $10-<10^{2}$ & 15 & $18.8 \%$ & 6 & $15.8 \%$ \\
\hline $10^{2}-<10^{3}$ & 58 & $72.5 \%$ & 28 & $73.7 \%$ \\
\hline $10^{3}-<10^{4}$ & 7 & $8.7 \%$ & 4 & $10.5 \%$ \\
\hline Total & 80 & $100 \%$ & 38 & $100 \%$ \\
\hline
\end{tabular}

Table 4: Incidence of Prototheca spp. in the examined samples:

\begin{tabular}{ccccc}
\hline Prototheca spp. & Buffaloes milk & \multicolumn{3}{c}{ Cow milk } \\
\cline { 2 - 5 } & No./100 & $\%$ & No./50 & $\%$ \\
\hline Prototheca zopfi & 7 & $7 \%$ & 0 & $0 \%$ \\
\hline Prototheca wickerhamii & 5 & $5 \%$ & 0 & $0 \%$ \\
\hline Total & 12 & $12 \%$ & 0 & $0 \%$ \\
\hline
\end{tabular}

\section{DISCUSSION}

Algae of the genus Prototheca are one of the few plant-like organisms that cause infections in humans and animals (Matsuda and Matsumoto, 1992; Möller et al., 2007; Marques et al., 2008). The pathogenesis of Prototheca organisms remains unclear, but they are believed to be of low virulence and mostly infect patients with various forms of immunosuppression (Jagielski and Lagneau, 2007).

The presence of microorganisms in milk, many of which are responsible for zoonoses, represents a factor that compromises its quality and safety. Therefore, bearing in mind the objective of reducing the microbial content of milk and also of eliminating microorganisms potentially harmful to humans, procedures for the thermal treatment of milk have been developed.

The present results showed that the average count of total yeasts and molds were $3.29 \times 10^{2}$ and $3.59 \times 10^{2}$ in the examined samples of both buffaloe's and cow's milk, respectively (Table 2 and 3 ) with minimum count $>10$ in both buffaloe's milk and cow's milk. Majority of positive samples occurs between $10^{2}-<$ $10^{3}$ in a percent of $72.5 \%$ and $73.7 \%$ in the examined samples of buffalo's and cow milk, respectively. High scores of CMT could be recorded in both samples of buffaloes and cow milk where 59 and $68 \%$ of examined samples where positive for CMT, respectively (Table 1).

Prototheca genus were isolated from subclinical mastitis buffaloes and shows a good development in aerobic conditions at $37{ }^{\circ} \mathrm{C}$ and the culture appears to be visible after 36 to 48 hours. The colonies are irregular ice crystal in shape (Fig., 1).

Table 4, revealed that Prototheca spp. are isolated in $12 \%$ of the examined buffaloes milk samples. $P$. zopfii detected in $7 \%$ while $P$. wickerhamii isolated from $5 \%$ of examined milk of buffaloes. Prototheca spp. were not detected in cow milk.

The reported level of infection within dairy herds is generally under $10 \%$ of milking cows. The present recorded results in this assay are relatively similar to 
that given by Buzzini et al. 2004 (4.7\% of samples possessed cells of Prototheca spp.). Also, our recorded results were in parallel with Benites et al., 1999; Corbellini et al., 2001; Bexiga et al., 2003; Kirk and Mellenberger 2011; who isolated P. zopfii from milk samples in percentages $9 ; 5 ; 2.2$ and 5.4, respectively. While some reports have shown higher rates of isolated $P$. zopfii with percentages of 10.7 39\% (Pore et al., 1983; Costa et al., 1996; Costa et al., 1997 and Jensen et al., 1998). Scaccabarozzi et al. (2008) could isolate P. zopfii from $11.9 \%$ of milk samples. Recently, Zaini et al. (2012) could identify four $P$. zopfii strains $(3.07 \%)$ from the 130 samples of dairy cattle with clinical mastitis and there was no isolation from totally 100 samples of healthy bovines without mastitis. While, Gao et al. (2012) isolated $P$. zopfii strains from 17 of 23 quarters, which suffered CM in the outbreak, and 7 of $46 \mathrm{CM}$ recovered quarters before the outbreak.

Comparing the present results by these obtained by Egyptian researcher, it is revealed that higher percentages of $P$. zopfii and P. wickerhamii (22.2\% and $9.3 \%$ ) were recorded by Horya, (2011) when 150 samples of raw milk were examined. On the other hand, Asfour and Metwally, (2010) documented that $P$. zopfii where isolated in $6 \%$ of examined raw buffaloes milk and in percentage $2.33 \%$ of raw cow milk.

P. wickerhamii is generally associated with human pathology presenting essentially cutaneous or subcutaneous lesions and also more rarely generalized infections (Zaitz et al., 2006; Hightower and Messina, 2007; Lass-Florl and Mayr, 2007; Narita et al., 2008).

The common belief is that the transmission of an infection caused by $P$. zopfii occurs by means of direct contact of mammary glands with other contaminated sources on the dairy farm. Several studies have been devoted to the exploration and characterization of environmental sources of $P$. zopfii in dairy herds (Costa et al., 1997; Scaccabarozzi et al., 2008 and Osumi et al., 2008). The wet weather may constitute an important risk factor in the multiplication and dissemination of the microalgae and result in the frequent reports of mastitis (Corbellini et al., 2001). It has been reported that this agent can induce a persistent infection with intermittent shedding, due to its ability to infect and survive in macrophages and to invade the udder tissue (Roesler and Hensel, 2003). Thus, the infected udders may act as a reservoir of P. zopfii in the herd.

Results of antimicrobial and antifungal susceptibility tests in vitro indicated that these strains were resistant to majority of tested drugs, with the only exception of amphotericin B, nystatin, streptomycin, gentamicin, and amikacin.
Studies on the in vitro and in vivo susceptibility profile of the Prototheca genus have revealed great resistance to conventional antimicrobial, antifungal and antiseptic drugs (Costa et al., 1996; Buzzini et al., 2004; Bueno et al., 2006; Marques et al., 2006). Prototheca spp. isolates were classified on the basis of current taxonomic guidelines and identified as $P$. zopfii. Susceptibility tests carried out in vitro by using 25 antibiotic compounds revealed that the strains of $P$. zopfii were susceptible only to nystatin and amphotericin B (58 and $33 \%$ of total strains, respectively). Treatment for mastitis caused by $P$. zopfii is generally unsuccessful because the strains show in vitro resistance to most antibiotics commonly used in veterinary practice (Buzzini et al., 2004). Our results were in agreement with some previous reports, which showed in vitro susceptibility of $P$. zopfii strains to these agents (Marques et al., 2006). Since there are still no drugs with proven clinical efficacy against protothecal mastitis, although our results indicated sensitivity to some drugs in vitro, this does not guarantee that the drugs can be used for therapy against infections with this microalga in cows. However, a proposal about tentative treatment for $\mathrm{CM}$ cases using these drugs has been offered to veterinarians of the dairy farm.

$P$. zopfii has become an important cause of bovine mastitis in many countries. In the present study, to better understand the occurrence of one clinical mastitis (CM) outbreak due to P. zopfii (Gao et al., 2012). P. zopfii is the most crucial organism that can cause protothecal $\mathrm{CM}$ associated with typical signs, including reduced milk production, increased density of the infected quarters, and thin watery secretion with white flakes (Ja'nosi et al., 2001 and Moller et al., 2007).

This study was also important from the point of view of veterinarian studies and humans' health since bovine mastitis can affect milk production by the cattle and reduce it. On the other hand, the $P$. zopfii is resistant to pasteurization and, therefore can easily transmit to its consumers and potentially cause health problems.

Consequently, more studies should be carried out in this field and in other geographical parts of Egypt, using more milk samples from bovines with mastitis in order to coordinate and confirm the results of this study. The results showed $P$. zopfii, is responsible for causing bovine mastitis in Iran as same as other geographical parts of the world (Möller et al., 2007; Aouay et al., 2008 and Osumi et al., 2008). Protothecosis is a zoonotic disease, which can be transmitted to the human by consuming milk and cause intestinal infections and enteritis because of its resistance to pasteurization (Melville et al., 1999). As a result, it is important and crucial to consider and 
identify these microorganisms in milk, because they can be potentially harmful to the human health.

We hope that this study paves the way for further studies and investigations to be carried out in this field.

\section{CONCLUSION}

Milk as well as dairy products, when contaminated with Prototheca spp., represent a potential means of transmission of this zoonosis. These data suggest that $P$. zopfii may represent a serious risk in the studied herd, and this microalga could be an important potential pathogen causing mastitis in dairy herds in Egypt. It is indefinite that the infection source of this outbreak came from environment or previously infected quarters. Therefore, more samples should be collected from other environment sites and lactating quarters to define sources of this microalga. P. zopfii, due to its wide antibiotic resistance, could represent a serious risk in the studied herd. Providing clean and dry surroundings, improving milk procedures and culling chronically infected cows may contribute to prevent mastitis caused by this microalga.

Since the teat canal is the portal of entry for $P$. zopfii, cleaning and disinfecting the teats, milking machines, and animal housing facilities with a proper germicidal agent are among the most important preventive measures against protothecal mastitis.

\section{REFERENCES}

A.P.H.A. (1992): Standard Methods for the Examination of Dairy Products. $13^{\text {th }}$ Ed., American Public Health Association. Academic Press, pp. 2062-2065.

Aalbaek, B.; Jensen, H.E. and Huda, A. (1998): Identification of Prototheca from bovine mastitis in Denmark, APMIS, 106, 4: 483-8.

Abdel-Rahman Horya, G.A.H. (2011): Incidence of Prototheca microorgansms in raw milk and locally manufactured dairy products in Assiut Governorate. PhD., Assiut uni., Fac. Vet. Med., Food Hyg. Dept.

Abhel, E.; Alexander, A.H.; Kleine, M.L. and Lichtman, D.M. (1980): Protothecal olecranon bursitis. J Bone Joint Surg; 62: 835-836.

Acha, P.N. and Szyfres, B. (2003): Zoonosis y Enfermidades Transmissibles Communes al Hombre y a los Animals, third ed. Organizacion Panamericana de la Salud, Washington.

Aouay, A.; Coppee, F.; Cloet, S.; Cuvelier, P.; Belayew, A. and Lagneau, P. (2008): Molecular characterization of Prototheca strains isolated from bovine mastitis. Med Mycol, 157: 1-4.
Asfour, Hanaa, A.E. and El-Metwally Abeer, E. (2010): Microbiological and Histopathological Studies on Prototheca Mastitis in Dairy Animals. Global Veterinaria, 4(4): 322-330.

Bakken, G. and Gudding, R. (1982): The interdependence between clinical and subclinical mastitis. Acta Agri. Scandin 32:17.

Benites, N.R.; Melville, P.A.; Guerra, J.L.; Sinhorini, I.L. and Costa, E.O. (1999): Prototheca zopfii electronic microscopy and histopathological evaluation of mammary glands infected by this alga. Napgama 1: 22-26.

Bexiga, R.; Cavaco, L. and Vilela, C.L. (2003): Isolation of Prototheca zopfii from bovine milk. Rev. Port. Cienc. Vet. 98: 33-37.

Bueno, V.F.; de Mesquita, A.J.; Neves, R.B.; de Souza, M.A.; Ribeiro, A.R.; Nicolau, E.S. and de Oliveira, A.N. (2006): Epidemiological and clinical aspects of the first outbreak of bovine mastitis caused by Prototheca zopfii in Goia's State, Brazil. Mycopathologia.

Buzzini, P.; Turchetti, B.; Facelli, R.; Baudino, R.; Cavarero, F.; Mattalia, L.; Mosso, P. and Martini, A. (2004): First large-scale isolation of Prototheca zopfii from milk produced by dairy herds in Italy. Mycopathologia.; 158(4): 427-30.

Chan, J.C.; Jeffers, U.; Gould, E.W.; Hutson, D.; Martinez, O.V.; Reddy, K.R.; Hassan, F. and Schiff, E.R. (1990): Visceral protothecosis mimicking sclerosing cholangitis in an immunocompetent host: successtul antifungal therapy. Rev Infect Dis; 12: 802-807.

Clinical and Laboratory Standard Institute (CLSI) (2004): Reference method for antifungal disk diffusion susceptibility testing of yeasts. Approved guideline. 1nd edn. Document M44A, Wayne, Pa, USA.

Corbellini, L.G.; Driemeier, D.; Cruz, C.; Dias, M.M. and Ferreiro, L. (2001): Bovine mastitis due to Prototheca zopfii: clinical, epidemiological and pathological aspects in a Brazilian dairy herd. Trop Anim Health Prod. 2001; 33(6): 463-70.

Cosmina, M.; Catoi, C.U.C.; Fit, N.; Nadas, G.; Rapuntean, S.; Taulescu, M. and Calina, D. (2009): Anatomical and histopathological researches in experimental infection with Prototheca algae in mice. Vet. Med., 66(1): 282-289.

Costa, E.O.; da, Carciofi, A.C.; Melville, P.A.; Prada, M.S. and Schaich, U. (1996): Prototheca sp. outbreak of bovine mastitis. J. Vet. Med.; 43: 321-324.

Costa, E.O.; Melville, P.A.; Ribeiro, A.R. and Watanabe, E.T. (1995): Relato de um caso de consumo de queijo fresco contaminado com Prototheca sp. In: Simpósio Brasileiro de Pesquisa em Medicina Veterinária, 1. São Paulo, Brazil: Anais, 55. 
Costa, E.O.; Melville, P.A.; Ribeiro, A.R.; Watanabe, E.T. and Parolari, M.C. (1997): Epidemiologic study of environmental sources in a Prototheca zopfii outbreak of bovine mastitis. Mycopathologia.; 137(1): 33-6.

Cox, G.E.; Wilson, J.D. and Brown, P. (1974): Protothecosis: a case of disseminated algal infection. Lancet; 2: 379-382.

Davies, R.R.; Speneer, H. and Wakelin, P. (1964): A case of human protothecosis. Trans Roy Soc Trop Med Hyg; 58: 448-451.

DiPersio, J.R. (2001): Prototheca and protothecosis. Clinical Microbiology Newsletter23, 115-120. Available online:<http://linkinghub. elsevier. com/retrieve/pii/.

Dubravka, M.S.; ljiljana, V. and Branka, and Vukosava, D. (2006): Outbreak of endemic form of protothecalmastitis on a dairy farm. Acta Veterinaria (Beograd).

Gao, J.; Zhang, H.; He, J.; He, Y.; Li, S.; Hou, R.; Wu, Q.; Gao, Y. and Han, B. (2012): Characterization of Prototheca zopfii Associated with Outbreak of Bovine Clinical Mastitis in Herd of Beijing, China. Mycopathologia, 173: 275-281.

Gaunt, S.D.; Mcgrath, R.K. and Cox, HU. (1984): Disseminated protothecosis in a dog. J. Am. Vet. Med. Assoc.; 185: 906-907.

Gómez-Hernando, C.; Palacio, A.; Nevado, M.; Carabias, E.; González, A.; Cuétera, M.S. and Carpintero, $Y$. (1996): Colonización transitoria por un alga (Prototheca wickerhamii) en un enfermo de cancer. Rev Theroam Microbiol 13: $56-58$.

Harrigan, W.F. and McCance, M.E. (1976): Laboratory Methods in Food and Dairy Microbiology. Academic Press Inc., London.

Heney, C.; Greeff, M. and Davis, V. (1991): Hickman catheter-related protothecal algaemia in an immunocompromised child. J Infect Dis; 163: 930-931.

Hightower, K.D. and Messina, J.L. (2007): Cutaneous protothecosis: a case report and review of the literature. Cutis 80, 129-131.

Hodges, R.T.; Holland, J.T.S.; Neilson, F.J.A. and Wallace, N.M. (1985): Prototheca zopfii mastitis in a herd of dairy cows. N.Z. Vet. J., 33:108.

Huerre, M.; Ravisse, P. and Solomon, H. (1993): Human protothecosis and environment. Bull Soc Pathol Exot; 86: 484 - 8.

Iacoviello, V.R.; Degirolami, P.C.; Lucarini, J.; Sutker, K.; Williams, M.E. and Wanke, C.A. (1992): Protothecosis complicating prolonged endotracheal intubation: case report and literature review. Clin Infec Dis; 5: 959-967.

Jagielski, T. and Lagneau, P.E. (2007): Protothecosis. A pseudofungal infection. J. Mycol. Méd., 17: 261-270.
Janosi, S.; Ratz, F.; Szigeti, G.; Kulcsar, M.; Kerenyi, J.; Lauko, T.; Katona, F. and Huszenicza, G. (2001): Review of the microbiological, pathological, and clinical aspects of bovine mastitis caused by the alga Prototheca zopfii. Vet Q.; 23(2): 58-61.

Jensen, H.E.; Aalbaek, B.; Bloch, B. and Huda, A. (1998): Bovine mammary protothecosis due to Prototheca zopfii. Med. Mycol, 36, 2: 89-95.

Kaminski, Z.C.; Kapila, R.; Sharer, L.R.; Kloser, P. and Kaufman, L. (1992): Meningitis due to Prototheca wickerhamii in a patient with AIDS. Clin Infect Dis; 15: 704-706.

Kaplan, W.; Chandler, F.W.; Holzinger, E.A.; Plue, R.E. and Dickinson, R.O. (1976): Protothecosis in a cat: first recorded case. Sabouraudia; 14: 281-286.

Kirk, J. and Mellenberger, R. (2011): Mastitis control program for Prototheca mastitis in dairy cows. http://milkquality.wisc. edu/wp-content/ uploads/2011/09/mastitis-control-program prototheca-mastitis.pdf.

Kirk, J.H. (1991): Diagnosis and treatment of difficult mastitis cases. Agri-practice; 12: 15-20.

Laeng, R.H.; Egger, C.; Schaffner, T.; Borish, B. and Pedrinis, E. (1994): Protothecosis in HIVpositive patient. Am J Surg Pathol; 18: 12611264. London, pp. 631-643.

Lass-Florl, C. and Mayr, A. (2007): Human protothecosis. Clinical Microbiology Reviews 20: 230-242.

Marques, S.; Silva, E.; Carvalheira, J. and Thompson, G. (2006): Short communication: In vitro antimicrobial susceptibility of Prototheca wickerhamii and Prototheca zopfii isolated from bovine mastitis. J. Dairy Sci.; 89(11): 4202-4.

Marques, S.; Silva, E.; Kraft, C.; Carvalheira, J.; Videira, A.; Huss, V.A. and Thompson, G. (2008): Bovine mastitis associated with Prototheca blaschkeae. J. Clin. Microbiol.; 46(6): 1941-5.

Matsuda, T. and Matsumoto, T. (1992): Protothecosis: a report of two cases in Japan and a review of the literature. European Journal of Epidemiology 8: 397-406.

Melville, P.; Watanabe, E.; Benites, N.; Ribeiro, A.; Silva, J. and Garino, F. (1999): Evaluation of the susceptibility of Prototheca zopfii to milk pasteurization. Mycopathologia, 146: 79-82.

Migaki, G.; Font, R.L.; Sauer, R.M.; Kaplan, W. and Miller, RL. (1982): Canine protothecosis: review of the literature and report of an additional case. J Am Vet Med Assoc; 181: 794-797.

Möller, A.; Truyen, U. and Roesler, U. (2007): Prototheca zopfii genotype2-the causative agent of bovine protothecal mastitis? Vet. Microbiol., 120: 370-374. 
Narita, M.; Muder, R.R.; Cacciarelli, T.V. and Singh, N. (2008): Protothecosis after liver transplantation. Liver Transplantation 14, 1211-1215.

Nosanchuk, J.S. and Greenberg, R.D. (1973): Protothecosis of the olecranon bursa caused by achloric algae. Am. J. Clin. Pathol.; 59: 567-573.

Osumi, T.; Kishimoto, U. and Kano, R. (2008): Prototheca zopfii genotypes isolated from cow barns and bovine mastitis in Japan. Vet. Microbiol., 131: 419-423.

Pore, R.S. (1998): Prototheca and Chlorella. In: Ajello, L., Hay, R.J. (Eds.), Topley and Wilson's Microbiology and Microbial Infections, $9^{\text {th }}$ ed., vol. 4. Arnold Publ.

Pore, R.S.; Barnett, E.A.; Barnes Jr., W.C. and Walker, J.D. (1983): Prototheca ecology. Mycopathologia 81: 49-62.

Pore, R.S.; Barnett, E.A.; Barnes, J. and Walker, J.D. (1983): Prototheca ecology. Mycopathologia; 81: 49-62.

Ricchi, M.; Goretti, M.; Branda, E.; Cammi, G.; Garbarino, C.A.; Turchetti, B.; Moroni, P.; Arrigoni, N. and Buzzini, P. (2010): Molecular characterization of Prototheca strains isolated from Italian dairy herds. J. Dairy Sci. 2010; 93(10): 4625-31.

Roesler, U. and Hensel, A. (2003): Longitudinal analysis of Prototheca zopfii-specific immune responses: correlation with disease progression and carriage in dairy cows. J. Clin. Microbiol.; 41(3): 1181-6.

Roesler, U.; Mo“ller, A.; Hensel, A.; Baumann, D. and Truyen, U. (2006): Diversity within the current algal species Prototheca zopfii: a proposal for two Prototheca zopfii genotypes and description of a novel species, Prototheca blaschkeae sp. nov. Int. J. Syst Evol Microbiol.; 56(Pt6): 1419-25.

Sands, M.; Poppel, D. and Brown, R. (1991): Peritonitis due to Prototheca wickerhamii in a patient undergoing chronic ambulatory peritoneal dialysis. Rev Infect Dis; 13: 376-378.

Scaccabarozzi, L.; Turchetti, B.; Buzzini, P.G.; Pisoni, L.; Bertocchi, N.; Arrigoni, P.; Boettcher, P.; Bonzo, V. and Moroni, P. (2008): Short Communication: Isolation of Prototheca Species Strains from Environmental Sources in Dairy Herds. J. Dairy Sci. 91:3474-3477.
Schalm, O.W. and Carrol, Jain N.C. (1971): Bovine mastitis. 1st Ed. Lea and Febiger, Philadelphia, USA.

Schuppel, H. and Schwope, M. (1998): Diagnosis of mastitis using California mastitis test and measurement of electric conductivity. Archiv für Lebensmittel Hygiene, 49: 61.

Segal, E.; Padhye, A.A. and Ajello, L. (1976): Susceptibility of Prototheca species to antifungal agents. Antimicrob Agents Chemother. 1976; 10(1): 75-9.

Smith, C.G. (1980): Ultrastructural study of Prototheca salmonis and comparison with known isolates of Prototheca. Mycopathologia; 71: 95-101.

Taniyama, H.; Okamoto, F.; Kurosawa, T.; Furuoka, H.; Kaji, Y.; Okada, H. and Matsukawa, K. (1994): Disseminated protothecosis caused by Prototheca zopfii in a cow. Vet. Pathol; 31: 123-125.

Tortorano, A.M.; Prigitano, A.; Dho, G.; Piccinini, R.; Dapra, V. and Viviani, M.A. (2008): In vitro activity of conventional antifungal drugs and natural essences against the yeast-like alga Prototheca. J. Antimicrob Chemother.; 61(6): 1312-4.

Ueno, R.; Urano, N. and Suzuki, M. (2003): Phylogeny of the non-photosynthetic green micro-algal genus Prototheca (Trebouxiophyceae, Chlorophyta) and related taxa inferred from SSU and LSU ribosomal DNA partial sequence data. FEMS Microbiol Lett.; 223(2): 275-80.

Venezio, F.R.; Lavoo, E.; Williams, J.E.; Zeiss, C.R. and Caro, W.A. (1982): Mangkornkanok-Mark M, Phair JP. Progressive cutaneous protothecosis. Am. J. Clin. Pathol.; 77: 485-493.

Wirth, F.A.; Passalacqua, J.A. and Kao, G. (1999): Disseminated cutaneous protothecosis in an immunocompromised host: a case report and literature review. Cutis; 63: 185-8.

Zaini, F.; Kanani, A.; Falahati, M.; Fateh, R.; Salimi-Asl, M.; Saemi, N.; Farahyar, Sh.; Kargar Kheirabad, A. and Nazeri, M. (2012): Identification of Prototheca zopfii from Bovine Mastitis. Iranian J. Pub.1 Health., 41(8): 84-88.

Zaitz, C.; Godoy, A.M.; Colucci, F.M.; de Sousa, V.M.; Ruiz, L.R.; Masada, A.S.; Nobre, M.V.; Muller, H.; Muramatu, L.H.; Arrigada, G.L.; Heins-Vaccari, E.M. and Martins, J.E. (2006): Cutaneous protothecosis: report of a third Brazilian case. Int. J. of Dermat. 45, 124-126. 


\section{مدي تواجد ميكروب البروتوسيكا في اللبن المنتج من القطعان الحلابة في مدينة أسيوط مروة محمد نبيل الجندي ، لمياء محمد طلعت علي الثريف}

التهاب الضر ع تحت الاكلينيكى احد أهم المشاكل الصحية التني تصيب الحيو انات الحلابة على مستوى العالم و التي تسبب خسائر فادحة

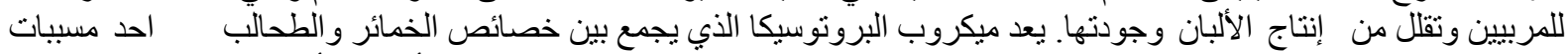

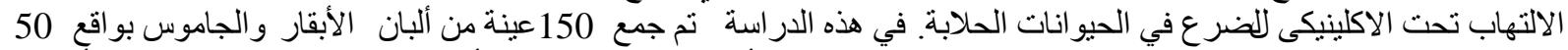

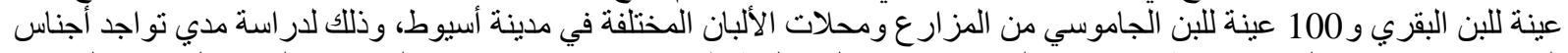

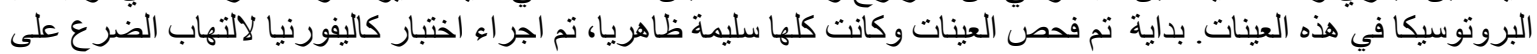

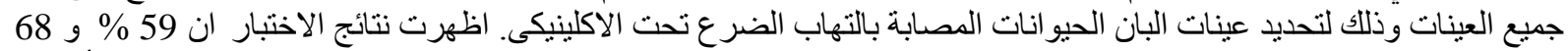

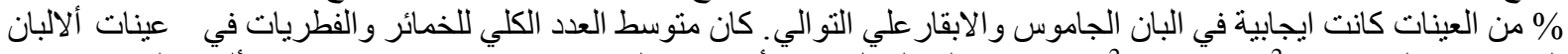

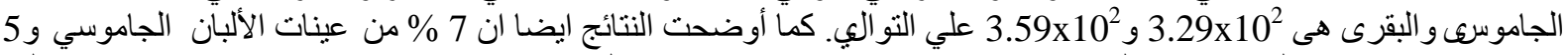

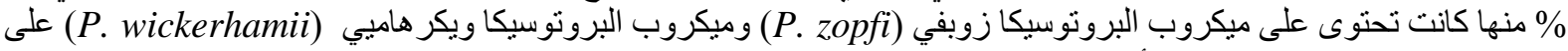

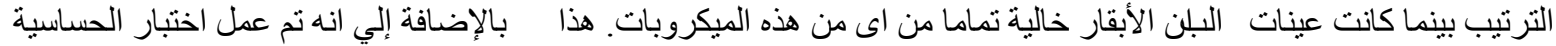
للميكروبات المعزولة لبعض المضادات البنات الحيوية للفطريات و البكتيريا. 